\title{
EXPERIÊNCIA DE PESQUISA EM DANÇA: NARRATIVAS DE DIFERENTES CORPOS DA LICENCIATURA EM DANÇA DO PARFOR/ETDUFPA
}

\author{
EXPERIENCIA DE INVESTIGACIÓN EN DANZA: NARRATIVAS DE \\ DISTINTOS CUERPOS DEL BACHILLERATO EN DANZA DEL PARFOR/ \\ ETDUFPA
}

\section{DANCE RESEARCH EXPERIENCE: NARRATIVES OF DIFFERENT BODIES OF THE PARFOR/ETDUFPA DANCE DEGREE}

\author{
Ricardo Augusto Gomes PEREIRA ${ }^{1}$ \\ Carlos Jorge PAIXÃO ${ }^{2}$
}

RESUMO: O objetivo do presente estudo é analisar a experiência da pesquisa em dança no âmbito da Licenciatura em Dança no Programa de Formação de Professores da Educação Básica - PARFOR/ETDUFPA/UFPA, a qual foi desenvolvida em diversos municípios do estado do Pará e formou em torno de 68 professores de dança. Para discutir essa temática, questionamos a condição de corpo e conhecimento dos sujeitos formados nessa licenciatura, considerando que as memórias dos professores-cursistas entrelaçam dificuldades e superação pela via do acesso ao curso ao que se lançaram na aventura de fazer dança na escola. Observou-se, nas narrativas coletadas com os egressos, o protagonismo no ensino da dança nas escolas de Educação Básica no interior do estado. Tal situação conduz a perceber que prática e formação se confundem na experiência desses professores a partir dos conhecimentos aprendidos, rompendo principalmente com os paradigmas da dança como pertencente a camadas privilegiadas da sociedade, trazendo à luz os corpos, o cotidiano, a cultura e a experiência de sujeitos amazônicos.

PALAVRAS-CHAVE: Experiência. Dança. Formação de professores. Corpo. Pesquisa

RESUMEN: El trabajo tiene el objetivo de analizar la experiencia de la investigación en danza en el ámbito del Bachillerato en Danza en el Programa de Formación de Profesores de la Educación Básica - PARFOR/ETDUFPA/UFPA, que se ha desarrollado en diversas ciudades del estado de Pará y ha formado alrededor de 68 profesores de danza. Para discutir este tema, cuestionamos la condición del cuerpo y conocimiento de los sujetos formados en bachillerato, considerando que las memorias de los profesores que hicieron el curso entrelazan dificultades y superación por el camino del acceso al curso al cual han puesto en marcha la aventura de practicar la danza en la escuela. Se ha observado en las narrativas colectadas con los egresos, el protagonismo en la enseñanza de danza como perteneciente a las camadas privilegiadas de la sociedad, sacando a la luz los cuerpos, el cotidiano, la cultura y la experiencia de sujetos amazónicos.

${ }^{1}$ Universidade Federal do Pará (UFPA), Belém - PA - Brasil. Doutorando em Educação (PPGED/ICED). Mestre em Educação. ORCID: <https://orcid.org/0000-0002-1626-6378>. E-mail: pereiraric19@ gmail.com

${ }^{2}$ Universidade Federal do Pará (UFPA), Belém - PA - Brasil. Docente do PPGED/ICED. ORCID: <https://orcid.org/0000-0002-4528-9907>.E-mail: carlosjpaixao@hotmail.com

RPGE- Revista on line de Política e Gestão Educacional, Araraquara, v. 22, n. 3, p. 1198-1216, set./dez., 2018. E-ISSN:1519-9029. 
PALABRAS CLAVE: Experiencia. Danza. Formación de profesores. Cuerpo. Investigación.

ABSTRACT: The aim of the present study is to analyze the experience of dance research in the context of the degree in dance in the teacher training program of basic education parfor/ETDUFPA/UFPA, which was developed in several municipalities in the state of Pará and Formed around 68 dance teachers. To discuss this theme, we questioned the condition of body and knowledge of the subjects trained in this degree, considering that the memories of the teachers-trustees interweave difficulties and overcoming through access to the course to what they have launched in Dance Adventure in school. It was observed, in the narratives collected with the graduates, the protagonism in the teaching of dance in the schools of basic education within the State. This situation leads to the understanding that practice and training are mistaken in the experience of these teachers based on the knowledge learned, mainly breaking with the paradigms of dance as belonging to the privileged layers of society, bringing to light The bodies, the daily life, the culture and the experience of Amazonian subjects.

KEYWORDS: Experience. Dance. Teacher training. Body. Research

\title{
Introdução
}

\author{
“A música na praça, o boi fazendo graça é Ronaldo e seus meninos ensinando à \\ nação que o futuro tá no centro da cultura,da cultura popular. \\ E taca carimbó de Pinduca, de Lucindo, Cupijó, Verequete, Pavulagem dos \\ meninos, Eduardo, Taynara e Cavalero vão tocar no Preamar, Preamar". \\ A força que vem das ruas - Almirzinho Gabriel
}

Na Amazônia, a preamar acontece com a cheia diária dos rios que serpenteiam e entrecortam a região e renovam a vida das matas, da fauna, das pessoas que vivem desse ciclo e que dia após dia criam e recriam seus modos de vida e sustento daquilo que o rio lhes dá. Esse fenômeno se entrelaça com a cultura amazônica de maneira profunda, uma vez que é na preamar que se forjam mitos e lendas que povoam o imaginário da região: o Boto nas noites de lua cheia, a Matinta que pede tabaco, a Cobra Grande que passeia pelos rios amazônicos, a Mãe d'Água protetora dos igarapés, enfim, tudo começa e termina na preamar, porque é nela que o fluxo das águas comanda as vidas de ribeirinhos, de quilombolas, de indígenas, do povo da Vila da Barca, de parte do Jurunas e do Guamá, de Icoaraci e de Outeiro.

Eis a origem da cultura popular amazônica, que nasce na preamar e se torna uma pororoca, que se manifesta no carimbó que invade nossas almas e, como o samba, só não arrasta o pé quem já morreu. Nem no céu dá para ficar quieto, já que lá estão fazendo a festa com os mestres Lucindo e Verequete, que chama Mariana e as sereias do mar para 
rodar suas saias floridas no salão das estrelas e, como bem afirma o poeta, "ensinando à nação que o futuro tá no centro da cultura, da cultura popular".

Isso mesmo! Nós acreditamos nisso e fomos formar professores que traziam tudo isso em suas histórias de vida. Isso representava uma saída da zona de conforto, pois a formação de professores em dança para pessoas que desde criança faziam ballet clássico ou tiveram acesso a técnicas de Jazz, dança contemporânea ou mesmo danças parafolclóricas, que constituíram aprendizagens importantes à ensinagem da dança, era muito fácil, pois esse ensino se constituiria apenas em aprofundamento do que já se sabia, e isso não é nenhum demérito. Mas o desafio era outro: que pessoas eram essas que, presentes nas salas de aula, não tinham nenhuma aproximação com o universo da dança? Como ensinar técnicas de dança para quem nunca teve uma iniciação? Que corpos eram esses que iam se aventurar a dançar?

Acreditamos que essas questões se replicavam por todo o Programa de Formação de Professores da Educação Básica - PARFOR, e não somente sobre a licenciatura em dança, já que, apesar de anos de interiorização da UFPA, a instituição e seus vários institutos nunca tinham formado tantos professores em tão pouco tempo, sobretudo com os mesmos requisitos que norteiam a formação em Belém. No entanto, uma coisa era importante atentar em relação ao PARFOR, que era a formação docente, já que formar professores significava aperfeiçoar as habilidades para atuação na sala de aula, marcadamente reflexiva, metodológica e procedimental do currículo, diferente de uma formação bacharelesca revestida de licenciatura.

A licenciatura em dança e os demais 19 cursos implantados pela UFPA para formar professores foram desafiados a sair do conforto da sede e adentrar nos municípios do Pará que iam além da Universidade Multicamp, já que foram solicitadas turmas em Castanhal, Mãe do Rio, Santarém, Marabá, Tucuruí e tantos outros municípios que nunca tiveram a oportunidade de uma universidade chegar até seus territórios.

Esse protagonismo tem resultado em muitos aspectos que apresentarão efeitos no futuro da condução da Educação Básica no estado do Pará, uma vez que formar mais de 13.000 professores em nível superior é um feito grandioso diante das dificuldades geográficas e sociais, que representam grandes barreiras para o desenvolvimento da região e do país.

No entanto, nosso olhar neste texto se volta para além dos números e resultados alcançados por essa política pública, já que, durante o programa, sujeitos que nunca tinham tido acesso à universidade chegaram à academia trazendo suas experiências, seus corpos

RPGE- Revista on line de Política e Gestão Educacional, Araraquara, v. 22, n. 3, p. 1198-1216, set./dez., 2018. E-ISSN:1519-9029. 
marcados pela floresta, como também, no caso da Licenciatura em Dança, um ritmo próprio, legítimo, que trazia o lugar de origem como signo impresso no movimento pelos sujeitos no processo formativo. Observamos que essa perspectiva se entrelaça em enunciados que se articulam, como dito por Homi Bhabha (2010), em "espaços narrativos", cujo referido autor assevera que "o presente enunciativo na articulação da cultura é estabelecer um processo pelo qual outros objetificados possam ser transformados em sujeitos de sua história e de sua experiência" (BHABHA, 2010, p. 248).

Observamos que o acesso à licenciatura em dança no referido programa formou professores de dança em um viés diferente do que é preconizado no interior das universidades, uma vez que, no interior dessas, a pressão pela mantença de uma dança hegemônica, elitista e aprisionada a corpos delineados está em constante disputa com a concepção de dança a ser ensinada no âmbito da escola. Isabel Marques, em 1997, já anunciava tal conflito, afirmando que "se inter-relacionam, se ignoram, se cruzam, entreolham, multifacetando tanto o mundo da dança quanto o mundo da educação dedicado a ela" (MARQUES, 1997, p. 20).

Essa problemática no interior da formação ganha novos ares quando o referido curso sai de sua sede e adentra em diversos municípios paraenses, atingindo outros sujeitos que estão ensinando dança com outras virtuosidades além da técnica, que estão aprendendo a dançar para se posicionar com qualidade de vida, compromisso político e responsabilidade, confirmando o que Marques (1997, p. 21) esperançosamente afirma ao dizer que "a escola é hoje, sem dúvida, um lugar privilegiado para que isto aconteça e, enquanto ela existir, a dança não poderá continuar mais sendo sinônimo de 'festinhas de fim-de-ano"".

Dançar para viver, se conhecer, dançar para investigar a cultural do lugar, para se entender, para entender o outro, foram e são marcas da licenciatura em dança, mas que nesse Programa se diferencia pelos sujeitos que se propuseram a ensinar artes cênicas pela lente da dança, que, segundo Barreto (2004, p. 101),

A dança é um fenômeno que sempre se mostrou como expressão humana, seja em rituais, como forma lazer ou como linguagem artística. Neste sentido, ela é uma possibilidade de expressão e também de comunicação humana que, através de diálogos corporais e verbajs, viabiliza o autoconhecimento, os conhecimentos sobre os outros, a expressão individual e coletiva e a comunicação entre as pessoas.

Essa definição de dança contempla plenamente o Projeto Pedagógico de Curso (PPC) que abrigou a licenciatura abordada, executada pela Escola de Teatro e Dança da 
UFPA (ETDUFPA), a qual preconizou a formação do professor-pesquisador em artes/dança, conduzindo os estudos formativos pelos seguintes vieses:

Ser profissionais aptos a atuar na Educação Básica, em escolas de Educação Infantil, Ensino Fundamental e médio com ensino específico de Dança; Possibilitar, como professor(a), a pesquisa científica em Dança visando à criação, compreensão e difusão da cultura dessa arte e seu desenvolvimento; Ser capaz de observar cada aluno, procurando rotas alternativas de ação para levar seus alunos a desenvolver-se plenamente, com base nos resultados de suas avaliações, sendo assim motivador e visando o desenvolvimento da autonomia no seu aluno [...] (ETDUFPA, 2011, p. 33).

Nesse artigo propomos uma reflexão a partir dos dados coletados junto aos alunos, professores e coordenadores da Licenciatura em Dança e da Coordenação Geral do PARFOR/UFPA, analisando narrativas em relação às categorias corpo, experiência, formação e dança, buscando relacionar o ensino das artes cênicas ao contexto do trabalho pedagógico na Educação Básica, o qual atualmente é amparado por uma série de legislações, na forma da Lei $n^{\circ} 11.769 / 2008$, que obriga o ensino da música, e da Lei ${ }^{\circ}$ 13.278/2016, que obriga o ensino de artes por linguagens de teatro, dança, artes visuais e música, cujo cruzamento é fundamental para a formação dos sujeitos que estão nas etapas e modalidades desse nível da educação nacional.

\section{Licenciatura em dança: uma experiência particular e coletiva de formar professores de dança}

A licenciatura em dança é uma célula pequena e poderosa que desde a sua concepção, em seu Projeto Pedagógico, já anunciava para que veio ao definir que formaria em nível superior professores pesquisadores que iriam atuar na Educação Básica do estado do Pará com a possibilidade de continuar seus estudos em nível de pós-graduação lato e stricto sensu, tudo isso apoiado na premissa da realidade amazônica, na criação artística e especialmente na pesquisa (ETDUFPA, 2011).

Como dito, o desafio de formar professores de arte em um estado amazônico não é tarefa fácil, uma vez que a dimensão geográfica e o difícil acesso a meios de comunicação, transporte e tecnologia para o desenvolvimento do curso se apresentavam como desafios que foram encarados pela coordenação e pelos professores efetivos e contratados como um compromisso com a expansão da dança, não somente como componente curricular, mas como uma prática de vida que é direito de todo cidadão. Daí a convenção de que o eixo que nortearia a formação seria o corpo, considerando que o entendimento dos professores

RPGE- Revista on line de Política e Gestão Educacional, Araraquara, v. 22, n. 3, p. 1198-1216, set./dez., 2018. E-ISSN:1519-9029. 
da licenciatura em dança na elaboração de seu PPC era de que "a produção acadêmica de estudiosos tem revelado importantes questões referentes ao corpo, com propósitos pedagógicos centrados na educação integrada, onde a mente é valorizada em sintonia com o corpo" (ETDUFPA, 2011, p. 29).

Essa concepção fundamentava-se na ideia de superação da dualidade entre corpo e mente proposta por Descartes no século XVIII, o qual compreendia que esses dois elementos não se misturavam e que o corpo assumia posição secundarizada diante da mente. O PPC da Licenciatura em Dança, ao longo da execução do curso, quebrou essa concepção ao buscar a técnica virtuosa em detrimento da técnica por ela mesma. Essa noção de técnica coaduna com o pensamento deleuziano de seus círculos de virtualidades que se assentam sobre o que é atual, uma vez que "Todo atual rodeia-se de círculos sempre renovados de virtualidades, cada um deles emitindo um outro, e todos rodeando e reagindo sobre o atual" (DELEUZE, 1996, p. 49).

Desse modo, Deleuze não se refere à virtualidade na perspectiva de valores, mas de algo real que não pode ser visto, mas sentido. A Licenciatura em Dança, em seu PPC, entendia que a formação atingiria pessoas que nunca tiveram acesso às técnicas de dança, mas que deveriam ser formadas para essa função, então a saída era encontrar uma metodologia que não prescindisse da técnica, mas que fosse além disso, atingindo a “[...] particularidade que lhe cabe, entendendo o mecanismo evolutivo do corpo, como uma ferramenta fundamental no processo de ensino aprendizagem, com ações de caráter consciente, sensível, inteligível” (ETDUFPA, 2011, p. 30).

Entendo que é isso que insere a Licenciatura em Dança do PARFOR/ETDUFPA nos círculos de virtualidades deleuziano, já que formar professores sem uma prática efetiva de dança é fazê-los compreender que sua necessidade se coaduna com o que Deleuze (1996, p.49) afirma ao expressar que "no centro da nuvem do virtual está ainda um virtual de ordem mais elevada... cada partícula virtual rodeia-se de seu cosmo virtual, e cada uma por sua vez faz o mesmo indefinidamente [...]".

Mas, que corpos foram formados pela ETDUFPA no PARFOR? 
Figura 01 - Turma de Licenciatura em Dança de Santarém (2012)

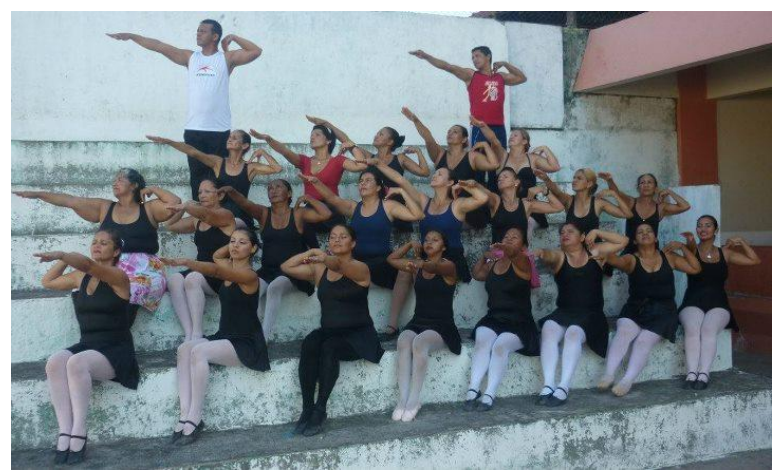

Fonte: Facebook. Perfil Licenciatura Dança Santarém (2015)

Acredito que a imagem responda à pergunta, pois os corpos que se apresentam na imagem vão além do virtual deleuziano, cuja forma é marcada por mulheres e homens que traduzem os quilombos, os furos, as estradas e as florestas, com toda a bagagem cultural que lhes permitiu a docência-pesquisa anunciada nos objetivos do curso.

Observo que essa imagem é para além da virtualidade, já que não se tem corpos perfeitos moldados pela técnica exaustiva do exercício físico ou da dança, mas aquilo que Deleuze e Guattari chamaram de corpo sem órgãos, no qual existe um plano de consistência e não propriamente técnica apurada, em que estão

[...] os princípios, como forças, essências, substâncias, elementos, remissões, produções; as maneiras de ser ou modalidades como intensidades produzidas, vibrações, sopros, Números. E enfim a dificuldade de atingir este mundo da Anarquia coroada, se fica nos órgãos [...] (DELEUZE; GUATTARI, 1996, p. 19).

Sem prescindir do ensino da técnica, a Licenciatura em Dança, pautada no eixo do corpo, preocupou-se em desenvolver uma pedagogia própria para essas turmas, de forma a fazer com que a dança fosse uma maneira de refletir sobre sua existência e sobre o fato de que dela é que emergem as forças aparentemente anárquicas, mas que representam a compreensão de si no mundo, o seu mundo do qual emerge a cultura local, sendo que "As manifestações da cultura popular local são consideradas elementos reveladores de estéticas, pensamentos e vivências que se transformam em poéticas e que fazem parte de ações que podem e devem ser inseridas no contexto educacional" (ETDUFPA, 2011, p. $31)$.

No percurso formativo, a possibilidade que o curso apresentou aos alunos foi bastante ampliada, já que no resgate da memória, observou-se a possibilidade de realização

RPGE- Revista on line de Política e Gestão Educacional, Araraquara, v. 22, n. 3, p. 1198-1216, set./dez., 2018. E-ISSN:1519-9029. 
de ações que ficaram no passado, impedidas pelos preconceitos, pela vida difícil, como é o caso de Josiane Corrêa (2017), do município de Capanema, a qual concluiu seu curso em 2013 e deixa claro em sua narrativa que:

[...] tinha vontade de participar das danças folclóricas, mas minha mãe não deixava por não ter condições para me arrumar, para mim a tristeza era grande demais. Percebo que essa prática que seria algo fácil de compreender e desenvolver os movimentos através da quadrilha devido a gostar de dançar e ter facilidade em aprender os passos ensinados [...]. Quando foi criada a quadrilha Rosa de Ouro, pra mim seria a chance de participar do grupo e dançar nos festivais, até comecei a ensaiar, desistindo com a primeira dificuldade em ter que ajudar nas tarefas de casa e conciliar os tempos de ensaio, e como não tinha o total apoio de minha mãe tudo se tornava mais difícil, com isso fui me entristecendo, chegando ao ponto de desistir de dançar.

Observa-se que as dificuldades financeiras eram um impedimento à participação da vida cultural de sua comunidade, sendo ressignificada na licenciatura ao possibilitar que seus alunos pudessem ter acesso à cultura popular por outros meios, pois atualmente a escola possui políticas que amparam o desenvolvimento de ações culturais em seu interior. As histórias de vida dos alunos da referida turma de Capanema se aproximam não só nas dificuldades, mas também na descoberta da possibilidade de dançar e ensinar dança na escola básica, cuja representação está presente na narrativa de Ozileide Pinheiro (2017), da mesma turma e município, que concluiu o curso em 2013:

Foi onde começou a minha vida com contato com a dança, na qual eu comecei a estudar o $2^{\circ}$ modulo, não tinha ideia do que era dança, na qual tive excelente professores que nos envolveram com suas metodologias inovadoras, desenvolvendo o universo da dança e nos proporcionando conhecimento que me servirão de apoio na minha carreira de professora de dança, que é a minha primeira licenciatura [...].

Assim, a perspectiva de formação para esses sujeitos - oriundos das escolas de Educação Básica, os quais muitos eram professores leigos, mas atuando com a formação de crianças - esteve voltada para a realização de um trabalho eminentemente didático e centrado no desenvolvimento do potencial físico, cognitivo e criativo dos alunos, uma vez que ensinar dança é, nos dizeres de Barreto (2004, p. 87), “para aquecer os corações duros e frios, maltratados por um longo inverno, para acariciar os olhos cansados de poluição e lágrimas, para acordar os ouvidos dos que perderam o jeito de ouvir a si mesmos e aos outros $[\ldots] "$. 
Em minha experiência como professor-colaborador do Programa, ministrando as disciplinas Trabalho de Conclusão de Curso I, II e Metodologia da Pesquisa Aplicada à Dança, ofertadas em todos os municípios, testemunhei a transformação de corpos e pessoas que ao longo da formação entenderam que dança é uma atitude e não simplesmente a aprendizagem de técnicas.

Assim, essas concepções implícitas ou explícitas mostram a seriedade com que essa formação é desenvolvida, já que o coletivo dos docentes que atuam na licenciatura realizam plenamente seu papel de professor-pesquisador que está na base do curso, evidenciando, dessa forma, o tripé de ensino-pesquisa-extensão que acontece em um grande processo investigativo a partir das identidades amazônicas, como se pode observar na Figura 02, em uma aula prática com a turma de Marabá no município de Itupiranga, às margens do Rio Tocantins.

Figura 02 - Turma de Marabá em Aula prática da disciplina Manifestações Espetaculares Brasileiras com o Prof. Dr. Éder Jastes, em Itupiranga

Fonte: Edilene Brito (2015)

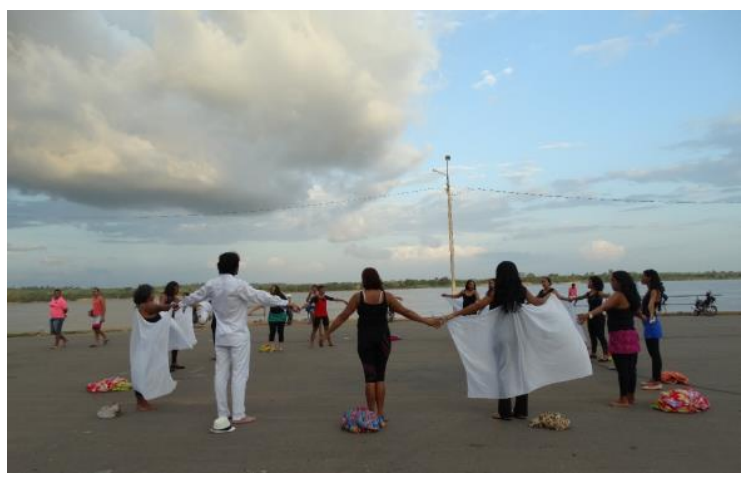

Na Figura 03, observa-se a presença de Pai e Mãe de Santo na defesa de TCC da aluna Vanda Melo, a qual analisou a presença de Terreiros e da Festa do Divino no bairro de São Felix, em Marabá.

Figura 03 - Vanda Melo na defesa do TCC sobre Terreiros e a Festa do Divino no Bairro de São Felix

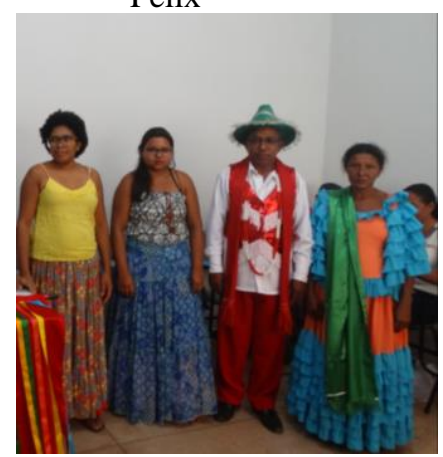

Fonte: Edilene Brito (2016)

RPGE- Revista on line de Política e Gestão Educacional, Araraquara, v. 22, n. 3, p. 1198-1216, set./dez., 2018. E-ISSN:1519-9029. 
Dessa forma, a identidade amazônica em sua multiplicidade tem permeado a execução do currículo da licenciatura em dança, ou, como afirma Paes Loureiro (2001) na obra "Cultura amazônica: Uma poética do imaginário", o trabalho que considera a cultura amazônica tem que ponderar que em qualquer manifestação o homem não está dissociado da natureza, na qual "perdura ainda uma harmonia, mesmo entrelaçada de perigos e se vive em um mundo que ainda não foi dessacralizado; em que o coração vive ardoroso do espírito e no qual brota ainda aquele leite e mel das sagradas origens" (LOUREIRO, 2001, p. 27).

Como docente dessa licenciatura, observo que o processo desenvolvido no curso traz consigo a marca de cada aluno e sua identidade, pois suas aprendizagens são registros de seus modos de vida e principalmente da cultura que os nutre, mostrando dessa forma que o texto do PPC se materializa na pesquisa realizada pelos alunos.

Ao propormos uma educação integral do corpo, concebido aqui como sistema, incluímos não apenas a subjetividade do indivíduo, mas também a cultura e o ambiente que o circundam. A complexidade permeia o pensamento das metáforas corporais e a sua relação com a evolução e o desenvolvimento da dança (ETDUFPA, 2011, p. 31).

No entanto, é preciso observar que a dança, no contexto do currículo da Educação Básica, está inserida em uma situação de secundarização extrema, potencializada pela atual reforma do Ensino Médio que relegou o ensino da arte à condição de disciplina optativa, sendo que já havia historicamente uma situação de clara apartação diante de disciplinas com maior carga horária no currículo, ficando em um plano inferior na preferência de estados e municípios. Reis (2003) salienta que mesmo com os avanços que a área de artes teve a partir da Lei de Diretrizes e Bases da Educação Nacional (LDBEN) e dos Parâmetros Curriculares Nacionais (PCN's), a referida área ainda é subalternizada na organização curricular das unidades escolares brasileiras, já que, além de cargas horárias diminutas, o autor referenda que,

[...] o ambiente físico e a dinâmica de funcionamento de muitas escolas, emerge a impressão de que muitos agentes educativos (professores, alunos e outros profissionais envolvidos com o trabalho escolar) ainda vivem em meados do século passado, principalmente quando confessam que não sabem mesmo o quê ensinar e para que aprender arte na escola (REIS, 2003, p. 65).

A observação do referido autor aponta um dos muitos desafios que a área de artes vive e que nos fazem compreender a baixa preferência pelos cursos dessa área no âmbito 
do PARFOR. Na Universidade Federal do Pará, o programa ofertou 391 turmas, sendo que as turmas de Dança são apenas duas, localizadas em Mãe do Rio e Tucuruí, representando 0,7\% das turmas em funcionamento no referido Programa.

Sobre a formação de professores oferecida pelo PARFOR, Santos (2015) aponta que, mesmo com relação aos cursos mais procurados por estados e municípios, essa demanda camufla exigências quanto ao desempenho dos alunos e a consequente culpabilização do professor pelo fracasso do ensino, ressaltando que "o professor sofre as pressões advindas da postura do discurso oficial de centralizar a qualidade da educação no papel do professor" (SANTOS, 2015, p. 96).

A análise sobre a Licenciatura em Dança, sua história no âmbito do Instituto de Ciências da Arte (ICA) e da ETDUFPA, sua situação em relação ao PARFOR, demonstra a seriedade com a gestão da instituição que se mostra organicamente integrada e comprometida com o desenvolvimento da Amazônia e com a valorização de sua cultura e identidade através dos sujeitos que trazem consigo as marcas dos rios, florestas e ancestralidades diversas.

Essa perspectiva está presente na compreensão de professores e coordenadores do PARFOR/ETDUFPA/UFPA, uma vez que esses professores são unânimes em afirmar que, na dimensão da dança, a formação do PARFOR avança na direção de ampliar essa prática no âmbito da escola e também dessa área enquanto ciência, já que "o conhecimento da dança e sua ciência não podem ficar presos a uma lógica linear do pensamento positivista, deve abrir-se para a intuição e buscar o ser integral", nas palavras de Garcia (2009, p. 64).

Essa referência é importante para compreender o entendimento de Ferreira, docente da UFPA há 25 anos, que atuou em vários municípios nos quais a Licenciatura em Dança foi implantada, a qual se posiciona apontando que o curso está, no estado Pará, adquirindo cada vez mais status de ciência:

Acho que foi uma porta que se abriu pra gente poder fazer a divulgação da dança no estado do Pará, com uma formação muito precisa, entendendo que a dança é uma área de conhecimento, entendendo que existe processos de ensinar a dança e essa dança dentro das muitas linguagens dos vários gêneros que existem de dança, entendendo a valorização dessa cultura da dança que existe em cada lugar, abrindo espaço para esses alunos, esses formandos que saíram do PARFOR iniciar projetos dentro de suas escolas e desenvolverem um processo de dança de uma forma mais ampla em termos de conhecimento (FERREIRA, 2018). 
O posicionamento dessa docente é importante na compreensão de que a formação dos professores de arte, mesmo sendo tratada como algo supérfluo, elitizado e para poucos, teve esse paradigma quebrado no PARFOR, uma vez que os sujeitos que se apossaram dessa formação eram pessoas que acumulavam experiência de sala de aula, mas que nunca tinham tido a oportunidade de se constituir professor em uma universidade pública, lugar de direito de cada um. Mas, além disso, esse acesso voltou o olhar dos professores formados para a dança que existe em cada lugar e para os processos educativos que a cultura pode desenvolver nas pessoas, o que Raymond Williams (2015, p.13), na obra "Recursos de esperança", afirma que somente a educação pode manter viva:

[...] A única forma de defesa está na educação, que pelo menos mantém vivas algumas coisas e que também, pelo menos em uma minoria, desenvolve modos de pensar e sentimentos capazes de entender o que está acontecendo, e de manter os mais requintados valores individuais.

Essa concepção de Williams aponta para o poder da educação, na qual o conjunto das artes cênicas tem papel importante na formação das pessoas e na perpetuação do que o referido autor chama de cultura, ao afirmar que "[...] uma cultura são significados comuns, o produto de todo um povo, e os significados individuais disponibilizados, o produto de uma experiência pessoal e social [...]" (WILLIAMS, 2015, p. 12).

Uma discussão sobre formação de professores de arte não seria suficiente se não incluísse a experiência, já que esta categoria atinge a dimensão estética do cotidiano por ser um evento que acontece ao longo da existência humana. Sobre isso, Dewey (2010), na obra "Arte como Experiência", afirma que as ideias não são fluidas ou etéreas, como pensam muitos quando se trata de arte, mas, ao contrário disso, são ações mentais que, no caso da arte, é mediada pela sensibilidade que Dewey afirma se expressar através de símbolos e também na interação entre o que ele chama de criatura/meio.

No caso dos sujeitos referenciados nesse texto, suas experiências são artísticas, estéticas e sociais, já que, envolvidos nos movimentos da cultura popular da Amazônia, se integram, criam e recriam a arte, a dança, o teatro, a música em aulas e movimentos culturais diversos, como dito por Telma Reis (2017), da turma de 2013 da Licenciatura em Dança de Capanema:

O Boi da Florinda é uma brincadeira que não é muito antiga, apesar de algumas pessoas que participaram hoje já estão aposentados, como algumas serventes. Mas se realiza todos os anos, tendo seu início de apresentações com duração de quinze minutos de apresentações. Do ponto de vista social, o Boi da Florinda representa a festa tradicional da 
escola, onde todos os anos, as crianças fazem toda uma preparação, uma organização e uma bela apresentação. Esse boi é importante por que transmite conhecimento e folclore popular e ao mesmo tempo resgata a cultura de antigas brincadeiras. O Boi da Florinda é uma manifestação que apresenta personagens que cantam, dançam e representam, e ao mesmo tempo personagens que dramatizam, como o vaqueiro que mata o boi, a sinhazinha que é a filha do fazendeiro.

Como é possível observar na narrativa de Telma Reis, o "Boi da Florinda" ganha ares educativos por se tratar de uma recriação com crianças de uma escola de educação infantil no referido município, que se inspira no boi bumbá, cuja manifestação é abundante na região bragantina, onde se localiza o município de Capanema. Mas é necessário interpretar a narrativa da referida aluna a partir da compreensão de que

[...] A experiência surge espontaneamente no ser social, mas não surge sem pensamento. Surge porque homens e mulheres (e não apenas filósofos) são racionais, e refletem sobre o que acontece a eles e ao seu mundo. Se tivermos de empregar a (difícil) noção de que o ser social determina a consciência social (THOMPSON, 1981, p. 16).

A perspectiva de Thompson parece plausível para compreender a relação entre experiência, cultura e educação, sobre a qual Alfredo Veiga-Neto (2003, p.11) aponta que é permeada por uma "[...] lógica única e o repertório comum de princípios, códigos, valores etc., comuns a todas as culturas e, por isso, partilhados por todas elas [...]". A prática pedagógica em torno do Boi da Florinda, como foi observado na narrativa de Telma Reis, está se tornando uma prática cultural pela experiência que professores, alunos e comunidade estão desenvolvendo juntos, atingindo outro grau de consciência social, o qual foi proporcionado pela ação da dança no espaço escolar.

Esta verificação constitui um trabalho investigativo sobre as impressões de egressos do PARFOR da Licenciatura em Dança sobre os usos da etnocenologia na prática pedagógica, mas que tem apontado outras categorias que neste texto, a partir das indicações da literatura em torno do tema, estão compondo o corpus teórico da pesquisa que subsidia a investigação em campo. A realização da pesquisa nessa política pública de formação de professores tem propiciado a análise da formação não ortodoxa, especialmente no campo da dança, mas para além da técnica, que revelam os objetos investigativos dos alunos e de estudo do cenário artístico presentes em rituais, cultos, cerimônias e interações sociais diversas, as quais se fundem no ato espetacular das manifestações, especialmente ligadas à cultura popular. Essa é a esperança dos resultados que pretendemos alcançar.

RPGE- Revista on line de Política e Gestão Educacional, Araraquara, v. 22, n. 3, p. 1198-1216, set./dez., 2018. E-ISSN:1519-9029. 
Outra constatação importante em relação ao processo investigativo é que o Programa de Formação de Professores da Educação Básica se constitui em um processo educativo de mão dupla, no qual a universidade cumpre com seu papel. Como diz Guimarães Rosa, "mestre não é quem sempre ensina, mas quem de repente aprende", e essa é a grande lição aprendida, uma vez que os professores cursistas do programa traziam saberes que interagiam com os saberes da ciência que habita as universidades.

\section{Um percurso que continuará em cada professor cursista...}

Peço permissão para apresentar uma imagem que considero simbólica, e representa que os esforços de todos os professores não foram em vão...

\section{Figura 04 - Turma da Educação Infantil do Prof. Nazareno Favacho em} Marapanim, em uma aula de dança

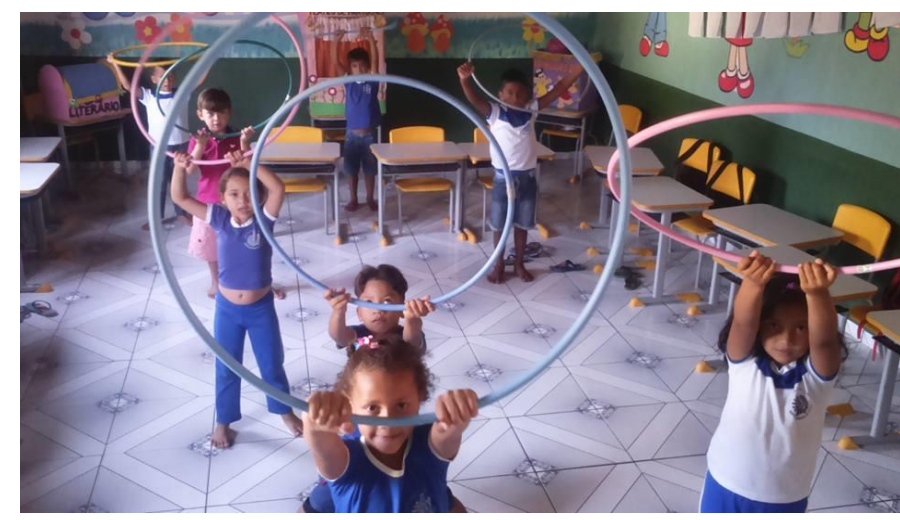

Fonte: Facebook. Perfil Nazareno Favacho (2016)

Através dessa figura podemos ter a certeza de que a licenciatura está cumprindo seu papel na direção de formar professores para a efetiva docência, pois não são professores bailarinos, mas professores que fazem da sua docência uma oportunidade de educar o corpo mediado pela cultura, verdadeiros e modelados pela realidade.

Como é possível observar nas figuras, a prática pedagógica dos egressos da licenciatura em dança não é guiada pela ordem técnica, mas por elementos relacionados à subjetividade do ato de interpretar, sobre o qual Bião (2007, p.2) considera outras formas de construção das artes dos espetáculos que traduzem a vida cotidiana ou "as formas de vida cotidiana, quando pensadas enquanto fenômenos espetaculares".

Essas formas de fazer dança permeadas pela prática pedagógica, como se pode observar na Figura 04, demonstra que a dança não é só movimento, mas também atos de linguagem cênica, sobre a qual Mendes (2010, p. 113) assinala que "Essa condição não diz 
respeito unicamente ao sentido temporal, mas refere-se, sobretudo, ao sentido estético da dança enquanto linguagem artística".

Prática e formação se confundem nas experiências dos professores que desenvolvem um modo de fazer dança diferenciado, mas relacionado à experiência humana com a cultura e com o cotidiano, já que a beleza reside na experiência estética produzida. Barreto (2004, p. 76) reafirma essa percepção, uma vez que “o sentido da dança é próprio da existência humana. Por isso só é possível compreender este sentido na experiência da beleza ou ainda nas experiências educacionais, recreativas ou ritualísticas".

A diversidade de formas de expressão cultural no interior dos municípios paraenses é a matéria prima para o trabalho cênico da dança dos professores formados pela Licenciatura em Dança do PARFOR/UFPA, e como a Figura 04 mostra, não só de cultura popular vive o professor de dança, mas da construção de modos de expressão, cujo norte é o corpo físico, social, místico de pessoas em construção de cidadania e isso implica dimensionar o corpo na forma social, como referenda Le Breton (2013, p. 8-9):

Cada sociedade, no interior de sua visão de mundo, delineia um saber singular sobre o corpo: seus elementos constitutivos, suas performances, suas correspondências etc. ela lhe confere sentido e valor. As concepções de corpo são tributárias das concepções de pessoa. Assim, numerosas sociedades não separam o homem de seu corpo, à maneira dualista, tão familiar ao ocidental. Nas sociedades tradicionais, o corpo não se distingue da pessoa. As matérias primas que compõem a espessura do homem são as mesmas que dão consistência ao cosmos, à natureza. Entre o homem, o mundo e os outros, um mesmo estofo reina com motivos e cores diferentes, os quais não modificam a trama comum.

Essa perspectiva é real quando se trata de Amazônia, pois essa região não é somente uma floresta abundante, mas um lugar de pessoas singulares detentoras de saberes, cujo corpo e ambiente são somente um e conduzem a vida das pessoas por caminhos difíceis, pois viver no interior da Amazônia não é fácil, como foi o caso de Genivaldo Silva, de Aveiro, no Baixo Amazonas, que cursou a licenciatura em dança na turma de Santarém em 2014. Apesar de o Estado e seus equipamentos estarem ausentes da população, ainda assim, esses sujeitos resistem e veem sentido no trabalho educativo da arte.

É bastante curioso você não saber uma coisa e querer, foi o que aconteceu comigo, e quando na hora de inscrever achei melhor ser um desafio de que somente ser um curso superior. Hoje vejo como outro horizonte que vai ser de fundamental importância para mim e para um bom desenvolvimento no meu trabalho escolar e para o meu crescimento intelectual. Fico muito entusiasmado ao ver o coreógrafo montado e 
executando seu trabalho coreográfico, saber que preciso de pouco para poder ter a facilidade de buscar dentro de mim a frutificação de conhecer, de buscar, de ir além do desconhecido, pela busca do querer, do querer para ensinar, para se doar, para não dificultar, mas sim para facilitar para um bom aprendizado dos alunos (SILVA, 2017).

A narrativa de Genivaldo Silva é uma representação do processo de transição entre o conhecimento da vida cotidiana e o conhecimento científico, que perpassa por outra consciência de corpo que, sem abandonar os conhecimentos tradicionais, se redimensiona a partir do necessário trabalho didático na ensinagem da dança na escola, e isso pode ser compreendido pela explicação de Le Breton (2013, p.10) ao relacionar que "O corpo da vida cotidiana implica ainda o emprego de uma sensibilidade. No início do século $\mathrm{XX}, \mathrm{G}$. Simmel esquematizou uma sociologia dos sentidos cujo princípio nós aqui retomamos ao lampejo das condições sociais e culturas [...]”.

Analisar o corpo como travessia, tendo o cotidiano como ambiente de onde emergem as sensibilidades necessárias para o trabalho didático em dança e demais artes cênicas na escola, revela a necessidade de lançar mão do científico aprendido na formação, como fez Marcelina Costa da mesma turma de Santarém, que concluiu o curso em 2014, cujo conhecimento lhe deu base para "[...] compreender as diferentes concepções de corpo humano ao longo da história da dança, a qual muito me chamou a atenção e ao mesmo tempo levou-me a investigar as diferentes concepções e construção acerca de corpo e movimento".

Essa narrativa contempla o fim a que se propõe o curso ao estabelecer como objetivo geral do PPC da Licenciatura em Dança o trabalho didático que a formação deverá imprimir na prática pedagógica do professor de dança na educação básica, definindo que,

[...] deverá criar, planejar, realizar, gerir e avaliar situações didáticas eficazes para aprendizagem e para o desenvolvimento dos alunos, utilizando o conhecimento das áreas a ser aprendido, das temáticas sociais transversais a matriz curricular escolar, bem como das respectivas didáticas (ETDUFPA, 2011, p. 32).

Observa-se que o PPC da Licenciatura em Dança se integrou com a prática efetiva, já que o conhecimento teórico, hoje, se transforma em práticas que formam os alunos nos rios, nas florestas, nos campos e nas cidades da Amazônia, que são muitas, pois elas vivem na experiência de cada pessoa e acabam por ensinar seus modos de vida como conteúdo curricular. Como diz Maués (2016), no Encontro Nacional do PARFOR em Londrina em 2016 , 
[...] construir uma outra relação com sujeitos com o tempo e o espaço, tendo a convicção de que nós sabemos muito pouco do que acontece efetivamente na vida dos professores, do que acontece efetivamente na sala de Educação Básica. Eu digo que os alunos do PARFOR não aprendem conosco, eles ensinam a universidade, eles mostram à universidade o nível de ignorância que temos em relação ao que é ensinar ao professor [...] (MAUÉS, 2016).

Ressalto que Maués é docente e exerce a função de Coordenadora Adjunta do Programa na Universidade Federal do Pará. Sua experiência nesse cargo lhe dá uma visão ampliada do processo de constituição do programa, como um processo educativo que não forma somente os professores da Educação Básica, mas forma a instituição, com seus saberes cristalizados, que precisaram ser revistos para atender e entender que a formação desenvolvida no interior da universidade nem sempre é a ideal para sujeitos oriundos das salas multisseriadas ou outros arranjos de classe, tempo e espaços que vivem, sobre palafitas, comunidades no meio da floresta, assentamentos e tantos lugares, onde o Estado não chega, mas o homem está lá e está fazendo educação nas condições que lhe são possíveis, que pela primeira vez foi possível ter contato e, principalmente, dialogar e construir com eles, no caso da dança, um currículo possível para esse ente das artes cênicas.

Por fim, há que se ressaltar que a pesquisa em dança se constitui um campo fértil de investigação, já que abre possibilidades para compreensão dos modos de vida e sua tradução em movimentos, processos criativos e recriações que fazem, não na forma regulada pelas regras da pesquisa científica e suas indexações, mas na relação com o público que se constitui ator junto com o autor. Na formação na Licenciatura em Dança no PARFOR o grande exercício foi justamente esse: fazer pesquisa na interação com a experiência, com a cultura e com as pessoas.

\section{REFERÊNCIAS}

BARRETO, Débora. Dança: ensino, sentido e possibilidades na escola. Campinas: Autores Associados, 2004.

BHABHA, Homi K., O local da cultura. 2. ed. Tradução de Myriam Ávila, Eliana Lourenço de Lima Reis, Gláucia Renate Gonçalves. Belo Horizonte: Editora UFMG, 2010. $441 \mathrm{p}$.

BIÃO, Armindo. Um trajeto, muitos projetos. In: BIÃO, Armindo (Org.). Artes do corpo e do espetáculo: questões de etnocenologia. Salvador: P\&A Editora, 2007. 492p.

CORRÊA, Josiane. Entrevistada. Capanema, jun. 2017. 
DELEUZE, Gilles. O atual e o virtual. In: DELEUZE, Gilles; PARNET, Claire.

Dialogues. Paris: Flammarion, 1996.

DELEUZE, Gilles; GUATTARI, Félix. Mil platôs: capitalismo e esquizofrenia. Vol. 3. Rio de Janeiro: Editora 34, 1996.

DEWEY, John. Arte como experiência. São Paulo: Martins Fontes, 2010.

ETDUFPA. ESCOLA DE TEATRO E DANÇA DA UNIVERSIDSDE FEDERAL DO PARÁ. Projeto Pedagógico do Curso de Licenciatura em Dança PARFOR. Belém: ICA/ETDUFPA, 2011. 118p.

FERREIRA, Eleonora. Entrevista concedida a Ricardo Pereira. Belém, 20 abril. 2018

GARCIA, Eliana Moraes et al. Dança e ciência: uma reflexão preliminar acerca de seus princípios filosóficos. Boletim Interfaces da Psicologia da UFRuralRJ. Rio de Janeiro: UFRRJ, v. 2, n. 1, 63-69pp, 2009. Disponível em:

http://www.ufrrj.br/seminariopsi/2009/boletim2009-1/garcia.pdf. Acesso em: 23 abr. 2018.

LE BRETON, David. Antropologia do corpo e modernidade. Tradução: Fábio dos Santos Creder Lopes. 3. ed. Petrópolis: Editora Vozes, 2013. 407p.

MARQUES, Isabel A. Dançando na escola. MOTRIZ. Volume 3, Número 1, junho/1997. 20-28pp. Disponível em: http://www.rc.unesp.br/ib/efisica/motriz/03n1/artigo3.pdf. Acesso em: 23 abr. 2018.

MAUÉS, Josenilda. Palestra encontro nacional do PARFOR. Londrina/ PR: 2016.

MENDES, Ana Flávia. Dança imanente: uma dissecação artística do corpo no processo de criação do Espetáculo Avesso. São Paulo: Escrituras Editora, 2010.

PAES LOUREIRO, João de Jesus. Cultura amazônica: uma poética do imaginário. São Paulo: Escrituras Editora, 2001.

PINHEIRO, Ozileide. Entrevistada. Capanema, jun. 2017.

REIS, Telma. Entrevistada. Capanema, jun. 2017.

REIS, William. Ensino de arte: um componente curricular obrigatório na Educação Básica. Cadernos de Pesquisa, São Luís, UFMA, v. 14, n. 2, 64-83pp, jul./dez. 2003. Disponível em: http://www.pppg.ufma.br/cadernosdepesquisa/uploads/files/Artigo205(18).pdf. Acesso em: 20 ago. 2016.

SANTOS, Jennifer Susan Webb. Possibilidades e limites no Curso de Pedagogia da Universidade Federal do Pará: a visão de egressos do Plano Nacional de Formação de Professores da Educação Básica-PARFOR. Belém: Programa de Pós-Graduação em Educação, Instituto de Ciências da Educação, Universidade Federal do Pará, 2015. 167 p. Dissertação (Mestrado). Disponível em: http://repositorio.ufpa.br/jspui/handle/2011/8459. Acesso em: 13 ago. 2016. 
SILVA. Genivaldo. Entrevistado. Santarém, jun. 2017.

THOMPSON, E. P. Miséria da teoria ou um planetário de erros: uma crítica ao pensamento de Althusser. Rio de Janeiro: Jorge Zahar Editores, 1981.

VEIGA-NETO, Alfredo. Cultura, culturas e educação. Revista Brasileira de Educação, n. 23, p. 5-15, maio./ago., 2003. Disponível em:

http://www.scielo.br/pdf/\%0D/rbedu/n23/n23a01.pdf. Acesso em: 23 abr. 2018.

WILLIAMS, Raymond. Recursos de esperança: cultura, democracia e socialismo. Editado por Robin Gable. Introdução de Robin Blackburn; tradução Nair Fonseca; Alexandre Peschanski. 1. Ed. São Paulo: Editora Unesp, 2015.

\section{Como referenciar este artigo}

PEREIRA, Ricardo Augusto Gomes.; PAIXÃO, Carlos Jorge. Experiência de pesquisa em dança: narrativas de diferentes corpos da licenciatura em dança do PARFOR/ETDUFPA. Revista on line de Política e Gestão Educacional, Araraquara, v. 22, n. 3, p. 1198-1216, set./dez., 2018. E-ISSN:1519-9029. DOI: 10.22633/rpge.v22i3.12039

Submetido em: 10/04/2018

Aprovado em: 15/06/2018 